\title{
Overall mortality among patients surviving an episode of peptic ulcer bleeding
}

\author{
Ana Ruigómez, Luis Alberto García Rodríguez, Göran Hasselgren, Saga Johansson, \\ Mari-Ann Wallander
}

\begin{abstract}
Study objective-The authors investigated whether patients who have survived an acute episode of peptic ulcer bleeding (PUB) have an excess long term all cause mortality compared with the general population free of PUB.

Design-Follow up study of previously identified cohort of patients with a PUB episode and a general population cohort. Setting-The source population included all people aged 30 to 89 years, registered with general practitioners in the United Kingdom.

Patients-All patients alive one month after the PUB episode constituted the cohort of PUB patients $(n=978)$. A control group of 5000 people was randomly sampled from the source population. The same eligibility criteria as for patients with PUB were applied to the control series. Also, controls had to be free of PUB before start date.

Main results-Relative risk of mortality among PUB patients was $2.1,95 \% \mathrm{CI}: 1.7$, 2.6) compared with the general population. This increased mortality risk occurred mainly in the patients less than 60 between men and women. The excess mortality was not only circumscribed to deaths attributable to recurrent gastrointestinal bleed, but also cardiovascular, cancer and other causes.

Conclusions-People who have survived an acute episode of PUB have a reduced long term survival compared with the general population. This reduction was stronger among middle age patients than in the elderly.
\end{abstract}

Centro Español de Investigación

Farmacoepidemiológica. years old. No difference was observed Madrid, Spain

A Ruigómez

L A García Rodríguez

Astra Hässle AB, Mölndal, Sweden

G Hasselgren

S Johansson

M-A Wallander

Department of Surgery, Göteborg University, Sweden

G Hasselgren

(F Epidemiol Community Health 2000;54:130-133)

Department of

Medicine, Göteborg

University

S Johansson

Department of Family Medicine, Uppsala University, Sweden M-A Wallander

Correspondence to: Dr L A García Rodríguez, Centro Español de Investigación

Farmacoepidemiológica, $\mathrm{c}$

Almirante 28, 2 ${ }^{\circ}, 28004$

Madrid, Spain

Accepted for publication 31 May 1999 suggested that patients with a peptic ulcer bleed have an excess long term mortality.

The main goal of this study was to estimate the overall mortality rate among patients who have survived an acute episode of peptic ulcer bleeding (PUB) and to compare their long term mortality with the one in the general population free of PUB. Also, we examined whether individual characteristics and clinical conditions predict long term survival.

\section{Methods}

DATA RESOURCE

The General Practice Research Database (GPRD) is a validated computerised health care data resource covering more than three million residents in the United Kingdom. Its characteristics and procedures have been described in detail in previous reports. ${ }^{9-11}$ Briefly, it includes information on demographics, medical diagnoses, referrals to consultant and hospital, outpatient prescriptions, as well as laboratory results and a free comments section. The general practitioner records the clinical information of all patients under their care, and then sends the data anonymised to the Office of National Statistics (ONS).

\section{STUDY POPULATION}

The source population includes all people aged 30 to 89 years old registered with general practitioners who collaborate in the GPRD data resource. We used data from a previous epidemiological study that examined the short-term mortality from PUB. ${ }^{12}$ There were 1020 patients identified as having been admitted to hospital and with a diagnosis of peptic ulcer bleeding involving the stomach and/or the duodenum (PUB) between 1 January 1991 and 31 March 1994. Patients presenting with haemorrhagic gastritis or duodenitis were not included. Patients with cancer, oesophageal varices, cirrhosis, Mallory-Weiss syndrome and intestinal vascular pathologies were excluded. All patients alive one month after the PUB episode constituted our cohort of PUB patients $(n=978)$, and their study start date was 30 days after the PUB episode. A control group of 5000 people was randomly sampled from the source population. A random date within the study period was assigned to each of them to be used as start date and the same eligibility criteria as for patients with PUB were applied to the control series. Also, controls had to be free of PUB before start date. We then followed them up from start date until the earliest of death or end of the study period (31 December 1995).

All patients dying during the follow up were identified and their computerised patient 
profiles were reviewed to ascertain the cause of death. We defined an upper gastrointestinal bleeding related death, as one occurring within 30 days of an UGIB episode subsequent to the study start date. Information on other factors related to survival was obtained from computerised files, and included age, sex, comorbidity, smoking status, body mass index (BMI), and units of alcohol consumed per week. This information was ascertained within a year of their start date, in a similar way for cases and controls. We categorised patients as abstainers or occasional drinkers, when they took less than two units per week, light drinkers from 2 to 15 units, and moderate to heavy drinkers when they took more than 16 units per week. ${ }^{13}$ Comorbidity status before start date was obtained for the following diseases using the International Classification of Disease, ninth revision (ICD-9) codes: cardiovascular diseases (ICD-9 codes 410-417,428-429), cerebrovascular disease (ICD-9 codes 430-437), respiratory disease (ICD-9 codes 480-496), osteoarthritis (ICD-9 codes 715), rheumatoid arthritis (ICD-9 codes 711,714 ), diabetes (ICD-9 code 250), and hypertension (ICD-9 codes 400404).

MORTALITY ANALYSIS

We calculated estimates of mortality rate and 95\% confidence intervals (CI) for the two study cohorts (PUB patients and general population). Patients alive at end of study period, those transferred to other practices or with their last practice visit before end of study were regarded as censored data at that date.

The Cox proportional hazards regression model was used to compute multivariate adjusted relative risk (RR) of mortality in the group of PUB patients compared with the general population. Included in the model were other risk factors such as age, sex, comorbidity, BMI, smoking and alcohol consumption. The appropriateness of proportionality assumption was examined graphically and statistically. ${ }^{14} \mathrm{We}$ evaluated whether the effect associated with PUB status was modified in various age strata, and between men and women. We examined the interaction by age of the association between PUB patients and mortality using as the reference group people from the general population, between 30 to 59 years of age.

\section{Results}

Table 1 presents the distribution of individual characteristics and other risk factors in the cohorts of PUB patients and general population. PUB patients were much older (mean age 64.4; SD =14.4) than the general population (mean age 52.7; $\mathrm{SD}=15.1$ ). There was a greater proportion of men and patients with chronic diseases in the cohort of PUB patients than in the general population. When adjusting for age and sex, the association between most of the chronic diseases and PUB status decreased substantially. There were no major differences in the distribution of smoking habit among the two cohorts.

One hundred and fifty five deaths occurred in the PUB cohort during a mean follow up of
Table 1 Characteristics of cohorts of peptic ulcer bleeding (PUB) patients and general population

\begin{tabular}{|c|c|c|}
\hline & $\begin{array}{l}\text { PUB patients } \\
(n=978)(\%)\end{array}$ & $\begin{array}{l}\text { General } \\
\text { population } \\
(n=5000)(\%)\end{array}$ \\
\hline \multicolumn{3}{|l|}{ Age } \\
\hline $30-59$ & $326(33.3)$ & $3319(66.4)$ \\
\hline $60-69$ & $239(24.4)$ & $816(16.3)$ \\
\hline $70-79$ & $261(26.7)$ & $630(12.6)$ \\
\hline $80-89$ & $152(15.5)$ & $235(4.7)$ \\
\hline \multicolumn{3}{|l|}{ Sex } \\
\hline Male & $616(63.0)$ & $2380(47.6)$ \\
\hline Female & $362(37.0)$ & $2620(52.4)$ \\
\hline \multicolumn{3}{|l|}{ Cardiovascular disease } \\
\hline \multicolumn{3}{|l|}{ Cerebrovascular disease } \\
\hline Yes & $74(7.6)$ & $123(2.5)$ \\
\hline \multicolumn{3}{|l|}{ Diabetes } \\
\hline Yes & $53(5.4)$ & $135(2.7)$ \\
\hline \multicolumn{3}{|l|}{ Respiratory disease } \\
\hline \multicolumn{3}{|l|}{ Hypertension } \\
\hline Yes & $222(22.7)$ & $606(12.1)$ \\
\hline \multicolumn{3}{|l|}{ Osteoarthritis } \\
\hline \multicolumn{3}{|l|}{ Rheumatoid arthritis } \\
\hline Yes & $45(4.6)$ & $66(1.3)$ \\
\hline \multicolumn{3}{|l|}{ Body mass index (BMI) } \\
\hline$<25$ & $300(30.7)$ & $1674(33.5)$ \\
\hline $25-30$ & $246(25.2)$ & $1306(26.1)$ \\
\hline$>30$ & $100(10.2)$ & $540(10.8)$ \\
\hline Unknown & $332(33.9)$ & $1480(26.6)$ \\
\hline \multicolumn{3}{|l|}{ Smoking } \\
\hline Non-smoker & $465(47.5)$ & $2597(51.9)$ \\
\hline Smoker & $238(24.3)$ & $1263(25.3)$ \\
\hline Ex-smoker & $85(8.7)$ & $276(5.5)$ \\
\hline Unknown & $190(19.4)$ & $864(17.3)$ \\
\hline \multicolumn{3}{|l|}{ Alcohol consumption } \\
\hline None/occasional & $241(24.6)$ & $1043(20.9)$ \\
\hline Light & $140(14.3)$ & $702(14.0)$ \\
\hline Moderate/heavy & $88(9.0)$ & $237(4.7)$ \\
\hline Unknown & $509(52.0)$ & $3018(60.4)$ \\
\hline \multicolumn{3}{|l|}{ Censor status } \\
\hline Death & $155(15.8)$ & $193(3.9)$ \\
\hline Alive at end study & $268(27.4)$ & $1956(39.1)$ \\
\hline $\begin{array}{l}\text { Censored at last visit to } \\
\text { GP }\end{array}$ & $522(53.4)$ & $2718(54.4)$ \\
\hline Transferred out & $33(3.4)$ & $133(2.7)$ \\
\hline
\end{tabular}

34 months (mortality rate 5.7 per 100 person years; 95\% CI: 4.9, 6.7), and 193 deaths occurred in the general population cohort during the 39 months mean follow up period (mortality rate 1.2 per 100 person years; $95 \%$ CI: $1.1,1.4$ ), Crude relative risk associated with having a PUB episode was 4.7 (95\% CI: $3.8,5.9)$. Cardiovascular disease was the most frequent cause of death in both cohort groups (table 2). Fourteen of the deaths in the PUB cohort $(9 \%)$ were related with an episode of UGIB, while only five $(2.6 \%)$ were in the general population. The proportion of deaths related to UGIB in the PUB cohort was similar in both young and elderly patients. As shown in table 2, the greater excess relative risk of dying among PUB patients was not only circumscribed to UGIB related deaths, but also to cancer, and other causes.

PUB patients had a twofold increased risk of mortality (RR: 2.1, 95\%CI: 1.7, 2.6) compared with the general population after adjusting for a number of risk factors (table 3). Age was the most powerful predictor of mortality during the four years of follow up. Cardiovascular, cerebrovascular disease and diabetes were also predictors of mortality. Among the life style variables, only smoking was associated with a significant increased risk of mortality. When we analysed the two cohorts separately, the effect of comorbidity and life style variables on 
Table 2 Distribution of causes of death in the cohort of PUB patients and general population and cause specific relative risk of mortality

\begin{tabular}{llll}
\hline & $\begin{array}{l}\text { PUB patients } \\
(n=155)(\%)\end{array}$ & $\begin{array}{l}\text { General population } \\
(n=193)(\%)\end{array}$ & $\begin{array}{l}\text { Relative risk } \\
(95 \% \text { CI })\end{array}$ \\
\hline UGIB related $\dagger$ & $14(9.0)$ & $5(2.6)$ & $9.6(3.2,28.6)$ \\
Cardiovascular disease & $47(30.3)$ & $72(37.3)$ & $1.7(1.2,2.5)$ \\
Cerebrovascular disease & $10(6.5)$ & $22(11.4)$ & $1.0(0.5,2.2)$ \\
Respiratory disease & $27(17.4)$ & $37(19.2)$ & $1.6(1.0,2.7)$ \\
Cancer & $20(12.9)$ & $19(9.8)$ & $3.3(1.7,6.2)$ \\
Other causes $\neq$ & $37(23.9)$ & $38(19.7)$ & $2.8(1.7,4.5)$
\end{tabular}

${ }^{\star} \mathrm{RR}$ associated with PUB status. Estimates are ajusted by age, sex, cardiovascular, cerebrovascular, diabetes and respiratory comorbidity, smoking, BMI and alcohol consumption. $†$ Death within 30 days of an episode of upper gastrointestinal bleed. ¥Information on cause of death was not available in $20(13 \%)$ of PUB cases and $26(14 \%)$ persons in the general population cohort.

Table 3 Adjusted relative risk of death from all causes associated with PUB status and other variables

\begin{tabular}{|c|c|c|}
\hline & $\begin{array}{l}\text { Deaths } \\
(n=348)\end{array}$ & $\begin{array}{l}R R \\
(95 \% C I)^{*}\end{array}$ \\
\hline \multicolumn{3}{|l|}{ PUB status } \\
\hline $\begin{array}{l}\text { General population } \\
\text { cohort }\end{array}$ & 193 & 1 \\
\hline PUB patients cohort & 155 & $2.1(1.7,2.6)$ \\
\hline \multicolumn{3}{|l|}{ Age at start date } \\
\hline $30-59$ & 30 & 1 \\
\hline $60-69$ & 66 & $5.5(3.6,8.6)$ \\
\hline $70-79$ & 138 & $11.4(7.5,17.2)$ \\
\hline $80-89$ & 114 & $18.8(12.1,29.1)$ \\
\hline \multicolumn{3}{|l|}{ Sex } \\
\hline Male & 180 & 1 \\
\hline Female & 168 & $0.8(0.6,1.0)$ \\
\hline \multicolumn{3}{|l|}{ Cardiovascular disease } \\
\hline No & 218 & 1 \\
\hline Yes & 130 & $2.4(1.9,3.1)$ \\
\hline \multicolumn{3}{|l|}{ Cerebrovascular disease } \\
\hline No & 292 & 1 \\
\hline Yes & 56 & $2.2(1.6,2.9)$ \\
\hline \multicolumn{3}{|l|}{ Diabetes } \\
\hline No & 309 & 1 \\
\hline Yes & 39 & $2.2(1.6,2.9)$ \\
\hline \multicolumn{3}{|l|}{ Respiratory disease } \\
\hline No & 247 & 1 \\
\hline Yes & 101 & $1.4(1.1,1.7)$ \\
\hline \multicolumn{3}{|l|}{ Smoking $\dagger$} \\
\hline Non-smoker & 143 & 1 \\
\hline Smoker & 65 & $1.4(1.1,2.0)$ \\
\hline Ex-smoker & 20 & $0.9(0.6,1.5)$ \\
\hline \multicolumn{3}{|l|}{ Body mass index (BMI) } \\
\hline$<25$ & 79 & 1 \\
\hline $25-30$ & 62 & $0.9(0.6,1.3)$ \\
\hline$>30$ & 24 & $0.9(0.6,1.5)$ \\
\hline \multicolumn{3}{|l|}{ Alcohol consumptiont } \\
\hline None/occasional & 91 & 1 \\
\hline Light & 24 & $0.6(0.4,1.0)$ \\
\hline Moderate/heavy & 10 & $0.7(0.4,1.3)$ \\
\hline
\end{tabular}

${ }^{\star} \mathrm{RR}$ estimates are adjusted by all the variables present in the table using Cox regression models. †Numbers may not add up to the total $(n=348)$ because of missing information, which was assigned to a separate category for the analysis.

mortality was of the same magnitude in the PUB and general population cohorts.

The increased mortality risk found among the PUB patients occurred mainly in the youngest age groups. As table 4 shows, the adjusted relative risk of dying among PUB patients aged 30 to 59 years was $7.0(95 \% \mathrm{CI}$ : $3.1,15.9)$ compared with the general population, while in the oldest age group $(80+)$ the RR was only 1.6 (95\% CI: $1.1,2.4)$.

In the general population cohort, the relative mortality risk in elderly (60+ years) was 15 times greater than in younger people of 30 to 59 years old (table 5). In the PUB cohort, the difference in mortality risk among the two age groups was smaller, approximately a threefold to fourfold increase. Indeed, young PUB patients were associated with a RR close to nine compared with the group of young general population, and elderly PUB patients pre-
Table 5 Adjusted relative risk of death associated with age and PUB status using a common reference group

\begin{tabular}{lc}
\hline & $R R(95 \% C I)^{*}$ \\
\hline General population cohort & 1 \\
30-59 years $\dagger$ & $15.1(8.9,25.4)$ \\
60+ years & $8.8(4.3,18.1)$ \\
PUB patients cohort & $30.7(18.1,52.0)$ \\
30-59 years & 60+ years \\
\hline
\end{tabular}

*Adjusted by sex, cardiovascular, cerebrovascular, diabetes, respiratory diseases, smoking status, BMI and alcohol consumption. $\nmid$ Common reference group.

sented a RR just over 30 . No effect modification of mortality risk by sex was observed (data not shown).

\section{Discussion}

People who have survived an acute episode of PUB have a reduced long term survival compared with the general population. Our study is the first one to compare survival experience between a large general population cohort and PUB patients. Our results show that patients after an episode of PUB carry a twofold greater risk of death compared with the general population. The increased long term excess mortality in PUB patients is noticeably higher at younger ages than at older ages. The impact of PUB on life expectancy is similar in men and women.

Previous studies on long term outcome of peptic ulcer haemorrage have generally included small series of patients, ${ }^{457}$ however none evaluated a general population cohort, hampering a direct comparison with this study. The mortality risk reported by Hudson et al in a recent study among elderly after an hospital discharge for PUB was similar to the one observed in our study. ${ }^{8}$ The authors reported a $50 \%$ survival probability at five year follow up among the PUB cases resulting in a RR of 1.7 (95\% CI: 1.5, 2.1) compared with expected death rates in England and Wales. When we restricted our cohort of PUB patients to subjects 60 years of age or older, the survival at four years was $68 \%$ and the adjusted RR of mortality compared with general population was 1.9 (95\% CI: 1.5, 2.4). Another study on late outcome of bleeding gastric ulcer patients also reported a significantly reduced survival rate (close to $60 \%$ at five years) compared with the one derived from national statistics. ${ }^{5}$ An Australian study on survival after a perforated peptic ulcer reported survival rate at 1,5 , and 10 years to be $78 \%, 60 \%$ and $46 \%$ respectively. These figures were barely lower than the expected ones in the general population based on national life tables statistics.

The cause of the reduced long term survival among patients who had suffered an episode of PUB compared with the general population remains unclear. PUB could be a marker of a general deterioration in health. Some studies have related this excess mortality to smoking and an excesive alcohol consumption among other factors. ${ }^{58}$ Our results were adjusted for BMI, alcohol use and smoking. Several other studies have attributed the increased mortality observed among patients with a peptic ulcer 
disease to comorbid conditions, ${ }^{48} 15$ and especially in elderly. In our study, we recorded history for the following chronic diseases: cardiovascular diseases, cerebrovascular disease, chronic respiratory disease, diabetes, osteoarthritis, rheumatoid arthritis, and hypertension. All but the three later ones were associated with an increased all cause mortality. As well as for alcohol use, smoking and BMI, our estimate of mortality risk among PUB patients was adjusted for all comorbidities.

The excess mortality observed among PUB patients during the study period was not only circumscribed to deaths from a new episode of gastrointestinal bleeding, but also from cancer, and other causes. This has also been documented by other authors. ${ }^{4-7}$ The twofold increased mortality risk in PUB patients compared with general population remained unchanged when we excluded the 19 deaths related to UGIB from the survival analysis. Of the 155 deaths among the PUB patients, only 14 occurred within 30 days of a new bleed episode. A recent study also reported few deaths resulting from recurrent ulcer complication. ${ }^{8}$ There has been a decrease in recurrent ulcer complication rates (including rebleed, perforation and death) compared with earlier studies in the 1980s. Hudson et al suggest that this reduction in recurrent complications of PUB in recent years may be because of the introduction of acid suppressing drugs in the treatment and prophylaxis of ulcer disease. However, agreement is not complete regarding a causal explanation for this mentioned association. ${ }^{16}$ We could not test this hypothesis and further research is needed to clarify this issue.

The group with the greatest mortality were elderly patients with PUB, although the long term prognostic importance of having had a PUB decreased substantially with age. Patients under the age of 60 years old carried a sevenfold increased risk of long term mortality compared with the general population with the same age and sex distribution. In persons older than 70 years, the mortality risk was less than twice greater than in the general population of same age and sex distribution. Competing risks could be a partial explanation for the observed decreased risk with increasing age. Indeed, older patients have more competing risk factors for death (presence of other comorbidity, treatment related complications, impaired activity and functions, etc) than younger persons. ${ }^{17}$ Therefore, the effect of a new risk factor (in this case having had a PUB episode) on survival
KEY POINTS

- Long term survival experience after an episode of upper gastrointestinal bleed has not been well studied.

- Patients after a peptic ulcer bleed have a reduced long term survival compared with the general population, especially middle aged patients.

would be expected to be smaller among elderly patients than in younger populations.

We thank the staff at the General Practice Database Research Company, and the participating general practitioners for their excellent collaboration. We also thank the Boston Collaborative Drug Surveillance Program (BCDSP) for providing access to the database.

Funding: this study was supported by a research grant of Astra Hässle.

1 Hunt PS, Hansky J, Korman MG. Mortality in patients with haematemesis and melena: a prospective study. $B M \mathcal{F}$ 1979;1:1238-40.

2 Rockall TA, Logan RFA, Devlin HB, et al. Incidence of and mortality from acute upper gastrointestinal haemorrhage in the United Kingdom. BMF 1995;311:222-6.

3 Katschinski B, Logan R, Davies J, et al. Prognostic factors in upper gastrointestinal bleeding. Dig Dis Sci 1994;39:70612 .

4 Branicki FJ, Coleman SY, Fok PJ, et al. Bleeding peptic ulcer: a prospective evaluation of risk factors for rebleeding and mortality. World $\mathcal{F}$ Surg 1990;14:262-9.

5 Røbæck-Madsen M, Fischer L, Thomsen H, et al. Late outRøbæck-Madsen $M$, Fischer L, Thomsen $\mathrm{H}$, et al. Late out-
come of bleeding gastric ulcer. Five to eight years'

6 Englund R, Fisher A. Survival following perforation of peptic ulcer. Aust N Z F Surg 1990;60:795-800.

7 Smart HL, Langman MJS. Late outcome of bleeding gastric ulcers. Gut 1986;27:926-8.

8 Hudson N, Faulkner G, Smith SJ, et al. Late mortality in elderly patients surviving acute peptic ulcer bleeding. Gut 1995;37:177-81.

9 Jick H, Jick SS, Derby LE. Validation of information recorded on general practitioner based computerised data resource in the United Kingdom. BMF 1991;302:766-8.

10 Jick H, Terris BZ, Derby LE, et al. Further validation of information recorded on a general practitioner based computerised data resource in the United Kingdom. Pharmacoepidemiol Drug Safety 1992;1:347-9.

11 García Rodríguez LA, Jick H. Risk of upper gastrointestinal García Rodríguez LA, Jick H. Risk of upper gastrointestinal
bleeding and perforation associated with individual bleeding and perforation associate
NSAIDs. Lancet 1994;343:769-72.

12 García Rodríguez LA, Ruigómez A, Hasslgreen G, et al. Comparison of mortality from peptic ulcer bleed between patients with or without peptic ulcer antecedents. Epidemiology 1998;9:452-6.

13 Perry IJ, Wannamethee SG, Walker MK, et al. Prospective study of risk factors for development of non-insulin dependent diabetes in middle aged British men. BMF 1995;310:560-4.

14 Norusis MJ. SPSS Advanced statistics 6.1.Chicago: SPSS Inc, 1994:275-328.

15 Rockall TA, Logan RF, Devlin HB, et al. Risk assessment after acute upper gastrointestinal haemorrage. Gut 1996; 38:316-21.

16 Fisher I, Madsen MR, Thomsen H, et al. Peptic ulcer hemorrhage: factors predisposing to recurrence. Scand $\mathcal{F}$ Gastroenterol 1994;29:414-18.

17 Welch HG, Albertsen PC, Nease RF, et al. Estimating treatment benefits for the elderly:the effect of competing risks. Ann Intern Med 1996;124:577-84. 